\title{
Recognition and Separation Technique of Fault Sources in Off-Road Diesel Engine Based on Vibroacoustic Signal
}

\author{
A. Merkisz-Guranowska ${ }^{1} \cdot$ M. Waligórski ${ }^{1}$
}

Received: 18 September 2016 / Revised: 14 December 2016 / Accepted: 21 December 2016 / Published online: 12 October 2018

(c) The Author(s) 2018

\begin{abstract}
Purpose Acoustic and vibration signals taken from engine often provide significant dynamic information on mechanical and thermodynamic system conditions. The failure characteristics with its quantity description point at the nature and intensity of an incorrectness during normal engine operation, giving the basic principles for more accurate process run monitoring and recognition of fault sources influenced on combustion process run.

Method Problems of failure recognition for CI engine systems have been described. Attributes are created for a combustion run, also for malfunctions in a real engine work maps. The additional new feature of a method is connected with taking into account an empirical signal of combustion runs for each cylinder units and having applied advanced procedures of vibroacoustic signal measures. The way of quantification of combustion changes with accompanying process characteristics in different signal domains was approximated. Accurate recognition and separation of fault cases in normal engine work cycles is the first step of a signal qualification.

Results and Conclusions Fault source detection for diesel engine was analyzed and its accuracy was considered to generate the features most sensible for a process changes. The obtained analyses prove that it is capable to extract fault components from vibroacoustic signal run and precisely calculate its intensity point estimators.
\end{abstract}

Keywords Combustion process · Direct injection diesel engine · Vibroacoustic signal decomposition · Diagnostic system · Digital signal assessment $\cdot$ Fault recognition and separation $\cdot$ Process efficiency and monitoring

$\begin{array}{ll}\text { Abbreviations } \\ a_{i} & \text { Vibration accelerations } \\ a & \text { Angle of a crankshaft rotation } \\ \text { DWT } & \text { Discrete wavelet transform } \\ \eta & \text { Overall efficiency } \\ \text { FFT } & \text { Fast Fourier transform } \\ f_{i} & \text { Frequency } \\ f_{j} & \text { Fault } \\ g_{\mathrm{e}} & \text { Specific fuel consumption } \\ G_{\mathrm{e}} & \text { Fuel consumption rate } \\ m_{\text {air }} & \text { Air mass } \\ M_{\mathrm{o}} & \text { Torque } \\ n & \text { Engine speed } \\ N_{\mathrm{e}} & \text { Effective power }\end{array}$

M. Waligórski

marek.waligorski@put.poznan.pl

A. Merkisz-Guranowska agnieszka.merkisz-guranowska@ put.poznan.pl

1 Faculty of Machines and Transport, Poznan University of Technology, Piotrowo 3, 60-965 Poznan, Poland
$N_{\text {e, nom. }} \quad$ Nominal effective power

$p_{\mathrm{c}} \quad$ Cylinder pressure

$p_{i} \quad$ Parameter value

$p_{\text {inj }} \quad$ Fuel injection

$s_{i} \quad$ Signal

$u_{\mathrm{sz}} \quad$ Peak value

$x_{i} \quad$ Input value

$y_{j} \quad$ Output value

\section{Introduction}

Expansion of carrying systems determines the negative environmental effects, directly affecting the functioning of individual ecosystems. About $30 \%$ of energy consumption and over $20 \%$ of $\mathrm{CO}_{2}$ emissions are associated with this transport activity. Proper transport management requires the inclusion of an increasing number of control criteria and variables to meet even more stringent requirements in this area (Fig. 1).

As partial criteria in the transport modeling and optimization processes are often being considered [1, 6, 7]: 


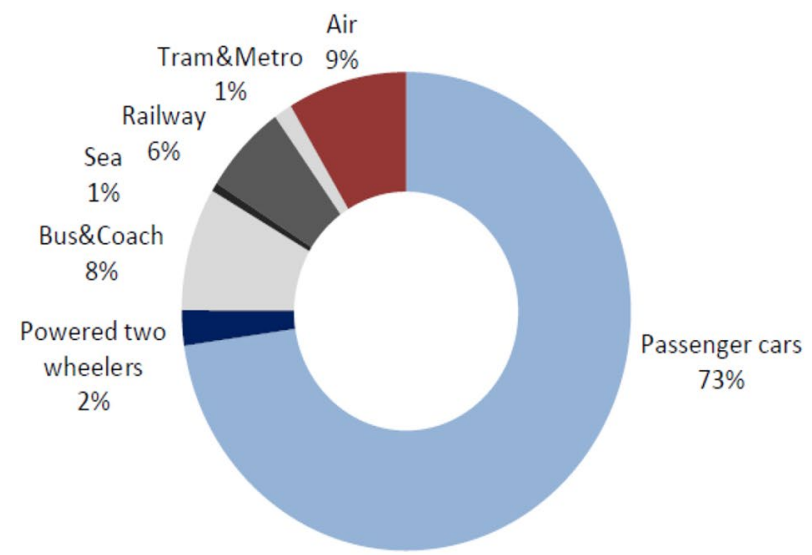

(a)

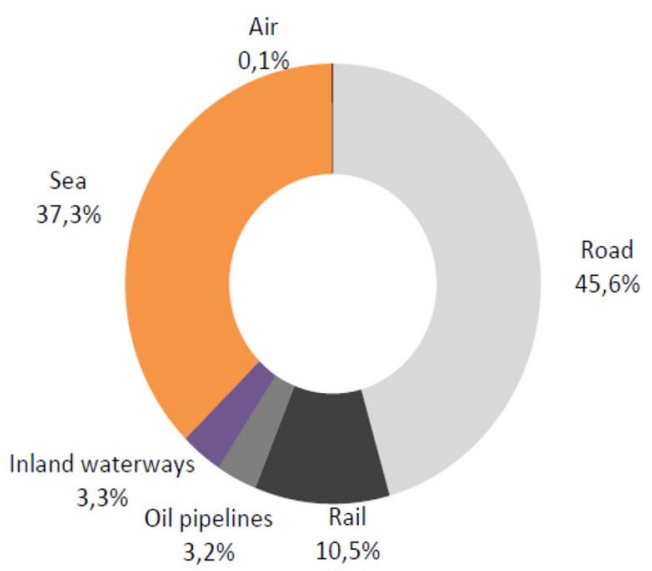

(b)

Fig. 1 Relative participation of maritime liners with \% pkm (a) and goods transport performance in \% tkm (b) for EU-27 [1]

- getting the lowest expenses of carriage,

- obtaining the shortest period of supply,

- maximizing the volume of distributed wares,

- creating the highest structure veracity,

- reaching the biggest conveyance assistance certainty,

- striving for the smallest amount of disgruntled claims.

An extremely important aspect for modeling of cartage processes is the inclusion of optimization of transport costs, both on the side of vehicle traffic dynamics, construction of a new infrastructure adapted to the specified overall efficiency of current and future vehicle drive systems, as well as traffic flow management, but also a real impact of transport systems on the ecosystems and their performances in different operational areas of their engines work. Sea transport is also crucial for such demands and its development is taken into account by international regulations and prospects for their changes.

\section{Diagnostic Models for Combustion Engine and Dynamic Processes Evaluation}

Technical state of the complex system is depicted with a set of states of its elements. The sources of these changes are faults, malfunctions and other events affecting the change in the quality of this system, among which may be mentioned those of a destructive nature and processes of cumulative wear, and returns to a balance state. Treatment of the engine as the object extracted from the environment and monitoring the interaction between the environment and the object are important in this case, and processes taking place during the engine operation, by the use of signal, defined as a run of any physical value that is a diagnostic information carrier. Obtaining this information is possible by determining the values of selected signal characteristics (process variables). They are measured values of signal characteristics, values calculated on the basis of other measured values or as steering signal values. Diagnostic signals can be obtained on the basis of them. Diagnosis is therefore a process of detecting and distinguishing object faults, malfunctions and incorrect processes runs as charging, transformation and evaluation outcomes of diagnostic signals [5]. Ensuring appropriate distinguishability of object damages or statuses is important in this case. The above fault detection and process irregularities detection are processes of diagnostic signals generation from the process variables. This evaluation therefore relates to mapping of process variable space in the space of diagnostic signals and evaluation of signal values to detect fault symptoms and their indication. Knowledge of the relationship between the diagnostic signals and states of malfunctions or technical states of diagnosing object is essential for this task. As a result, an appropriate design of the diagnostic system (algorithm) can be possible to assess fault indication, which in turn, depends on a set of algorithms and their detection accuracy.

Evaluated signals are generated by various sources, whereby the monitoring of a research object and its interactions with the environment are carried out. Due to the fact that the object of diagnosis is a dynamic system, a certain time passes from the symptom creation, depending on the dynamic properties of the tested object part. Therefore, negative values to outputs of these signals are present after a certain period of time, indicating the fault occurrence. Recognition of the object technical state or the quality of the monitored process run, based on information about a given object is accomplished by diagnosing, finding genesis and forecasting. Defining the object state or correctness of main or accompanying processes runs concerns handling of this state as a point in the space of range states, which

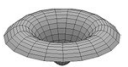


coordinates define the degrees of its placement of a state class taken into account. The proper selection of the model class to the system under test is appropriate process. Structural models, mapping machine element interactions, are often used in diagnostic tests. Thanks to them, it is possible to conclude effectively of the physical quantity types, as signals dependent on the object state and with the greatest sensitivity to its changes. In this case, diagnosing phases, detection, location and identification are important, aiming to evaluate irregularities and quantity changes that are present at combustion unit operation and forced by engine element damages.

Technical object systems can be divided into static and dynamic. In the first system, the response for input change is obtained immediately, while in the second system, it depends on the history of system changes. Static systems are described by algebraic equations, while the dynamic systems by differential equations, often nonlinear [3]. The object models for fault detection and fault location or object states classification can be used for used in the process diagnostics. The first of them is used to describe the relationship between the input and output signals and to detect changes that are caused by faults. Models for fault location determine the relationship between the diagnostic signals and damage, while the technical object state recognition is possible with the use of model mapping diagnostic signal space into object state space. Relations described in the technical object diagnostic process, concern (Fig. 2): the input-output relation (object model), the classifier input model features (transformation of quantitative features in quality features), the classifier output model features (transformation of quantitative features in quality features), the modified object model, the operation of model inversion, and searched inverse model (inference of a system class).

Models of the faults location should build an area of diagnostic indicators in discrete failure area (Fig. 3). The following diagnostic signals can be used as input signals in the process of fault localization: residues generated on the basis of the object model, binary or value signals on the basis of residue value assessment, binary or value signals generated with the classical or heuristic fault detection methods, statistical parameters

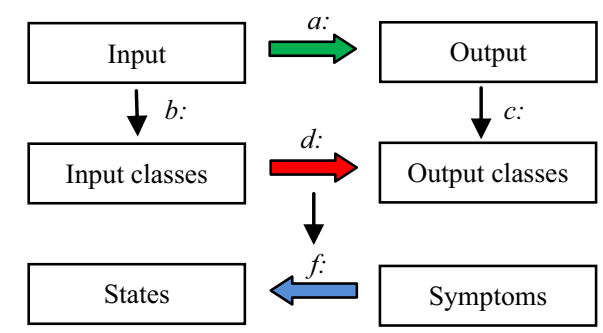

Fig. 2 Relation used in the machine diagnostics [3]

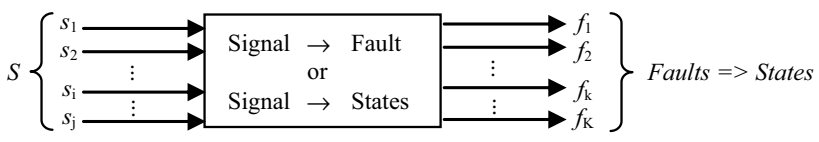

Fig. 3 Fault localization on the basis of diagnostic signal value assessment [3]

describing stochastic signal features, measured or calculated process variables of the signal physical values.

Detection is performed in an assessment of specified process variables by calculation and evaluation of the parameter value of this variable (e.g., mean value, RMS value)-Fig. 4.

Time history runs of main and accompanying process signals were used for the purpose of the analysis in the frequency domain. It should be established that the observed run is a stationary discrete process realization, according to hypothesis of ergodicity. In the normal work conditions of engine as a stationary object, specified process variables, which are stochastic signals, are described by specified shape of the autocorrelation function and function of power spectral density. When a fault occurs, it causes the specified change of the above characteristics. It makes possible to detect and localize faults and malfunctions in combustion engines during their operation. The spectral analysis is important for vibroacoustic diagnostics of machines. Distinctness of faults depends on the set of detection algorithms used in the diagnostic process. This set should be designed. The limitation is the set of measured signals; more signals cause more detection algorithms to be used. The set of detection algorithms is designed for an existing set of measured process variables.

The above paper is the second stage of the issues concerned in the author's paper [2]. In this part of a scientific authors' research is considered of techniques of the fault source recognition and separation for compression ignition engines, on the basis of accompanying process assessment.

\section{Research Methodology and Conditions}

The tests were performed in a laboratory at constant speeds and torques of the 4-stroke compression ignition engine [4]. All assumptions and analyses of the research methodology, combustion engine technical data and its work conditions chosen into account in the authors' studies, measurements stand and systems, are described in [2, 4]. The following

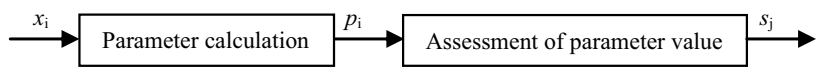

Fig. 4 Scheme of a diagnostic process with the control of process variable parameter value [3] 
methodological and research assumptions can be pointed at $[2,4]$ :

- measurement points for vibration signals were located on the engine heads (direction $Z$, vibration accelerations, 6 cylinders);

- measurements of sound pressure signals were located in four points (in front of engine, after eddy current brake, in front of engine perpendicularly to its crankshaft axis, above the engine);

- measurement system of Bruel and Kjær: PULSE 3560, 4384 and 4391 sensors, 4189 A-021 transducers;

- type of the experiment: active;

- measurement conditions: $f_{1}=f\left(N_{\mathrm{e}}\right), f_{2}=f\left(M_{\mathrm{o}}=\mathrm{idem}, n\right)$, $f_{3}=f\left(M_{\mathrm{o}}, n=\right.$ const. $)$

- diagnostic parameters: $p_{\text {inj }}, p_{\mathrm{c}}, G_{\mathrm{e}}, g_{\mathrm{e}}, \eta, L_{\mathrm{p}}, a_{i}$;

- type of measurement conditions: parallel signals recording with the sampling frequency of $24 \mathrm{kHz}$;

- constant thermodynamic engine state during measurement process in engine operating conditions;

- engine speed range (rpm): from $400 \mathrm{rpm}$ (idle run) to $750 \mathrm{rpm}$, with the speed interval $50 \mathrm{rpm}$;

- wide range of engine effective power factors, engine speeds for the $f_{2}$ function;

- acceleration parameters: $u_{\mathrm{sk}}, u_{\mathrm{sz}}, u_{\mathrm{rozst}}[4,5]$;

- engine characteristic range: overall efficiency of $18-37 \%$.

\section{Proposition of a Diagnostic Algorithm}

The dynamic system can be built with functions:

$$
\begin{aligned}
& \dot{x}(t)=\varphi[x(t), u(t), d(t), f(t)], \\
& y(t)=\psi[x(t), u(t), d(t), f(t)] .
\end{aligned}
$$

The state of the mechatronic system is dependent on the occurrence of structural and process failures of a determinate and stochastic nature. As a result of the operation process, changes in the geometric area and the quality of the engine's functioning are observed, affecting the form and nature of the state function and traffic equations. The developed algorithm takes into account the above dependence and follow-up of signals and their parameters, and the effects of its operation are parameters and diagnostic indicators determined for a given state and process variability (Fig. 5). Such algorism can be built also as emission-acoustic-related diagnostic procedures, on the basis of the algorithm presented in Fig. 5. Comparison of acoustic or vibration signal chosen characteristics with toxic emission compound parameters can be used for building of board diagnostic system sensible for emission changes and related with vibroacoustic estimators and frequency domain characteristic parameters (Fig. 6).
The created algorithm contains two parallel blocks of diagnostic tests. The first of them takes into account the toxic emission parameters and their changes in specified engine work area, while the acoustic related part of the diagnostic procedure concerns chosen sound pressure level characteristics as a function of engine brake power. Comparison of calculated values with the values for a normal engine work gives the important differences of model and measured signal estimators, and taking into account emission and acoustic estimators more precise diagnostic of the injection and combustion process taking place in combustion engine in specified operation conditions can be made.

\section{Combustion Process Assessment by Spectral Characteristics}

Before analyzing the vibroacoustic characteristics, one should state the engine working area taken into consideration in the studies. Authors of the presented papers chose a wide range of engine operational parameters in the research process, what gave them more information of the main and accompanying process functional relations taking place in this technical object. There are strict relations between fuel consumptions and overall efficiency and engine brake power for different engine operation conditions (Fig. 7). The above figures present indirectly the quality of main processes in combustion chamber during engine working cycles and for the each engine cylinder. Results on figures give the information that engine work is characterized by the range of values concerning the increase of overall efficiency, thus it means the engine combustion process is very efficient with the energy conversion in a mechanical work.

The above analyses indicate the injection and combustion processes for off-road diesel engine for maritime applications were being realized in a way to obtain a high value of process efficiency. Results of $\mathrm{CO}, \mathrm{HC}$ and $\mathrm{NO}_{x}$ emissions seem to confirm the above conditions of mixture formation and its combustion. It is visible that $\mathrm{NO}_{x}$ emission is a important task to be solved, particularly when one perceives the USA emission regulation changes for engines of maritime applications (Fig. 8).

Variation assessment of sound pressure level relating engine brake power proves its unequivocal functional relation for which the growth of the above engine operational parameter influenced the amplitude increase of the sound pressure signal. The last two graphs confirm the correlation of this pressure particularly from the speed; for torque, the observed differences were not higher than $2.1 \mathrm{~dB}$ (Fig. 9). That is why the engine speed should be considered in the diagnostic algorithms.

Time domain vibration acceleration runs pointed at significant increase of the signal amplitude with the increase of

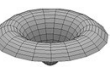


Fig. 5 The vibroacoustic algorithm of failures detection in injection and combustion processes runs at research offroad diesel engine

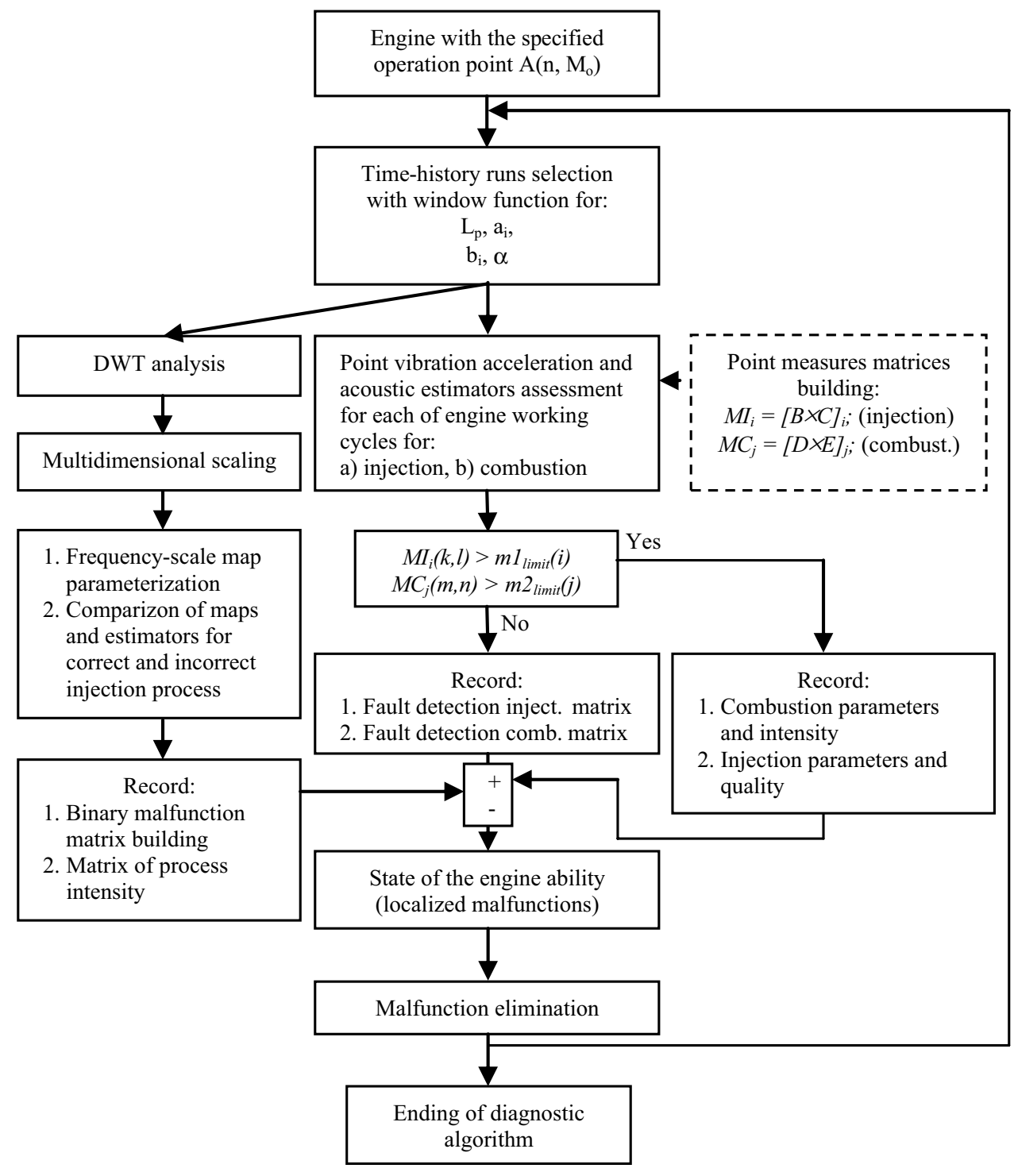

Engine with the specified

operation point $\mathrm{A}\left(\mathrm{n}, \mathrm{M}_{\mathrm{o}}\right)$

Time-history runs selection

$\mathrm{L}_{\mathrm{p}}, \mathrm{a}_{\mathrm{i}}$

$b_{i}, \alpha$

cstimators assessment

cycles for:

a) injection, b) combustion

$M C_{j}=[D \times E]_{j} ;$ (combust.)

1. Frequency-scale map

Comparizon of maps

nd estimators for

ect and incorrect

ection process

Record:

Binary malfunction

Matrix of proces

State of the engine ability

(localized malfunctions)

Malfunction elimination

Ending of diagnostic algorithm

is visible that there is an explicit representation of misfire phenomenon in the range $3000-5000 \mathrm{~Hz}$ of time-frequency signal characteristics. When engine brake power increase, the process period is longer and the intensity is higher, the same as for engine speed increase (Fig. 12).

\section{Conclusions}

The work contains the results of diagnostic analyses based on the proposed algorithms to assess the accuracy of the combustion process and detection of irregularities occurring in the presented short-time main signals and its lack.

Assessment of process variability is an issue recognized by framework of statistical analyses, for combustion process means the assessment of the repeatability of fast processes,

ciated with the stochastic components of the measurement path and interference from other processes. However, it 
Fig. 6 The emission and acoustic diagnostic algorism for off-road diesel engine

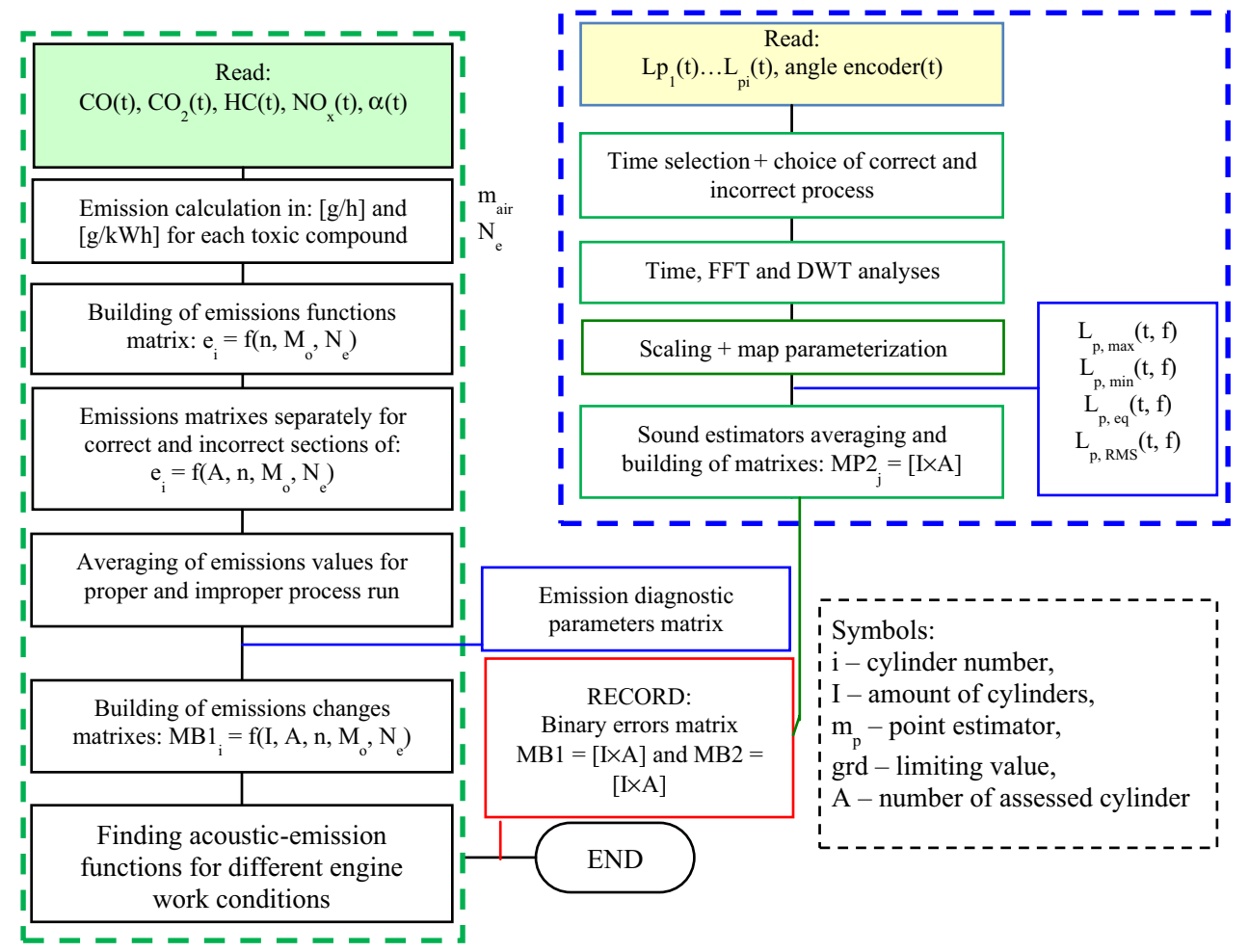

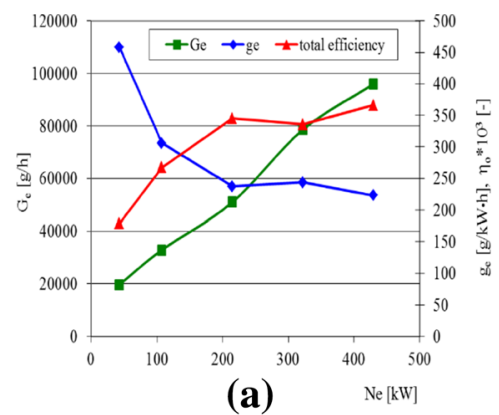

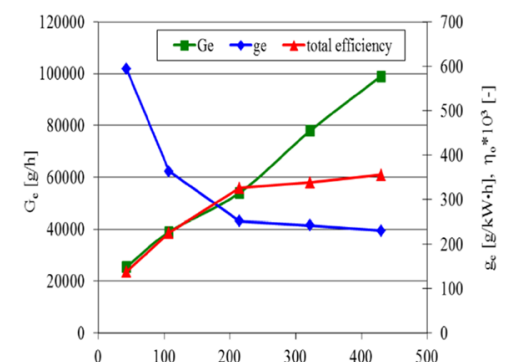

(b)

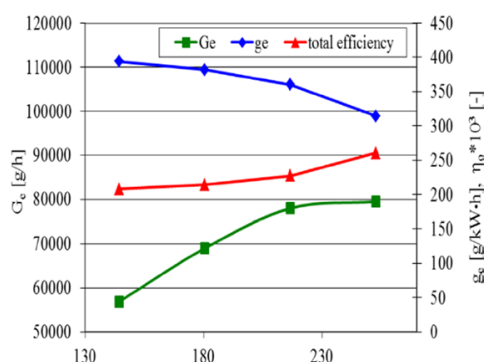

(c) $\quad \mathrm{Ne}[\mathrm{kW}]$

Fig. 7 Fuel consumptions $\left(G_{\mathrm{e}}, g_{\mathrm{e}}\right)$ and overall efficiency runs with engine brake power for the off-road diesel engine and the screw propeller (a), load (b) and partial power (c) characteristics

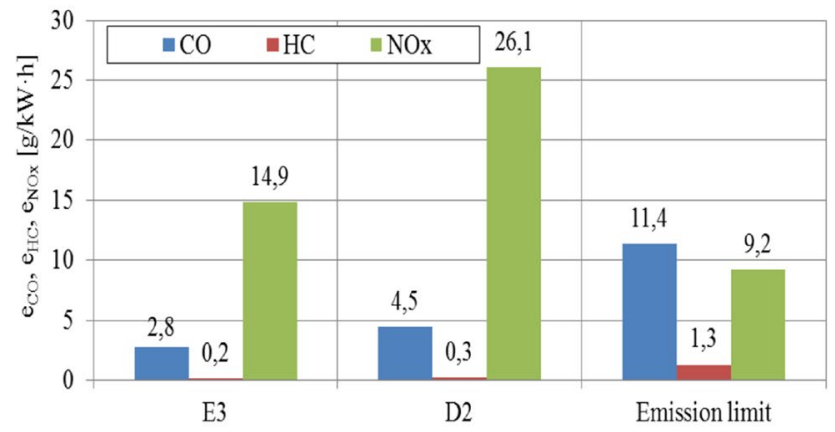

(a)

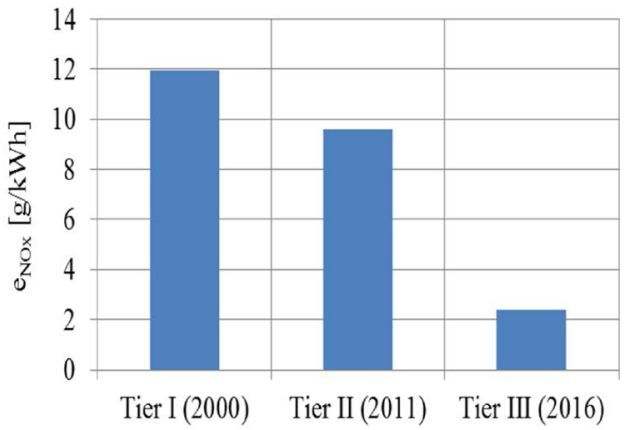

(b) Regulation type

Fig. 8 Emission of $\mathrm{CO}, \mathrm{HC}$ and $\mathrm{NO}_{x}$ for the off-road diesel engine and levels of $\mathrm{NO}_{x}$ emission limits for maritime applications 


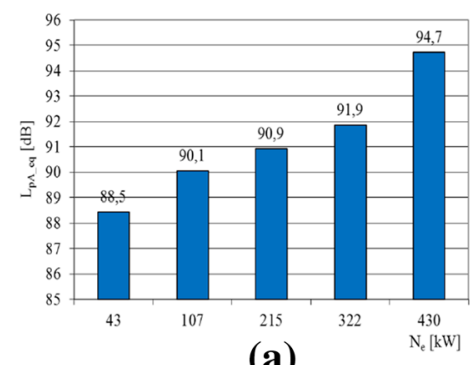

(a)

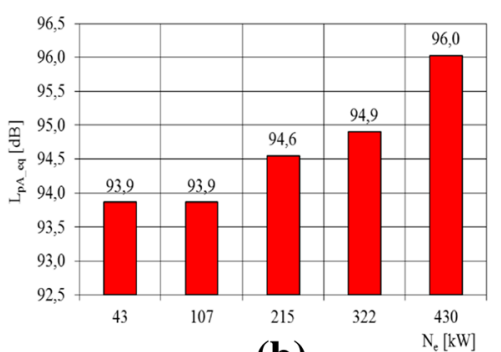

(b)

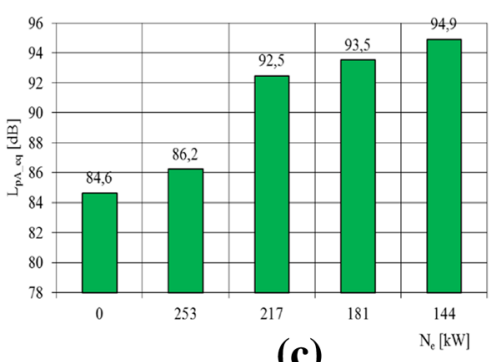

(c)

Fig. 9 Equivalent value of the sound pressure run with engine brake power for the off-road diesel engine and the screw propeller (a), load (b) and partial power $(\mathbf{c})$ characteristics
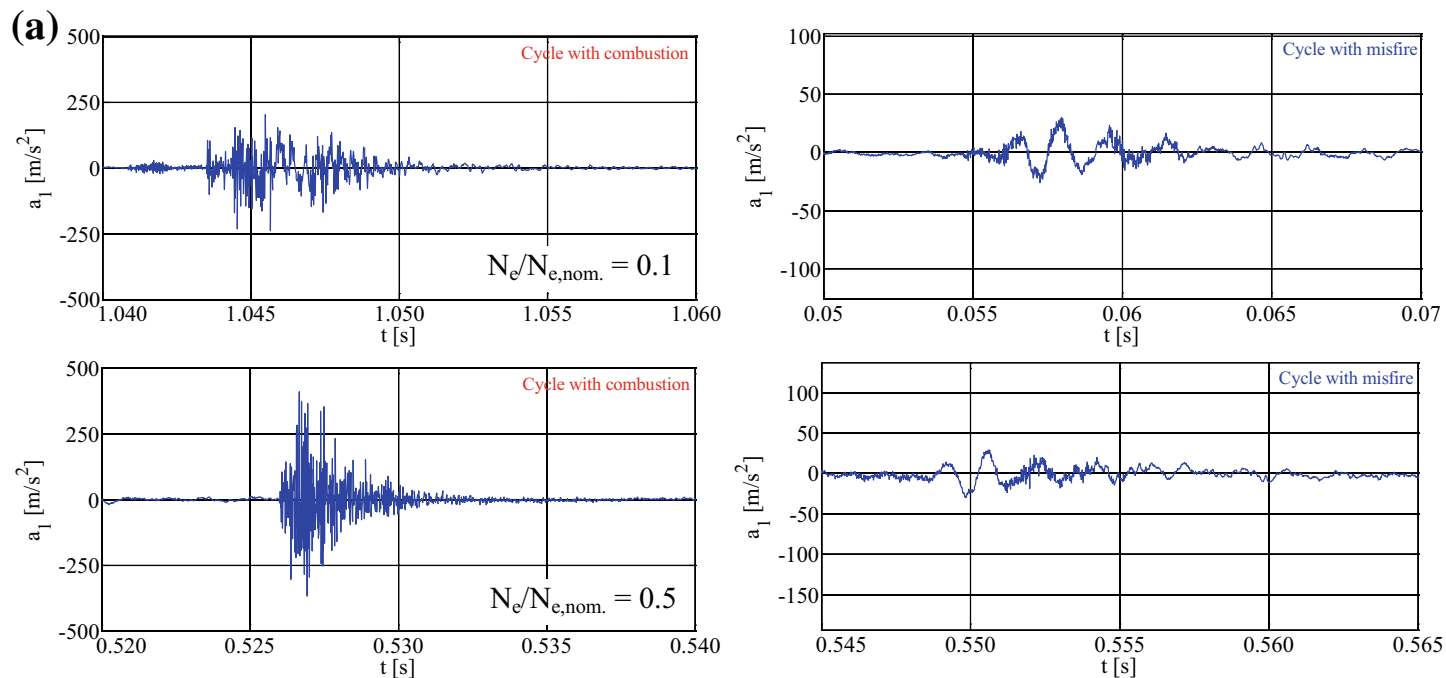

(b)
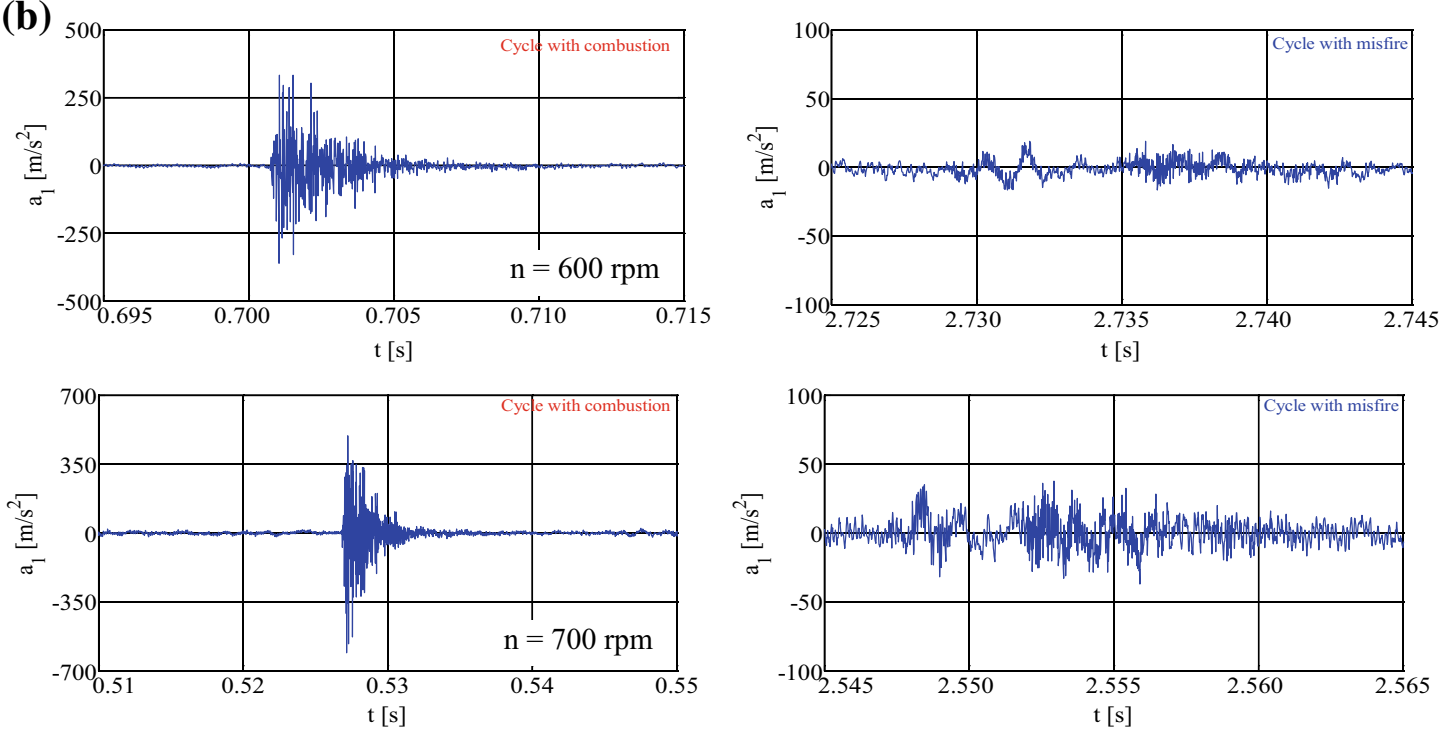

Fig. 10 Time history runs for cycles with the combustion and a misfire under conditions: a the propeller screw characteristics $\left(N_{\mathrm{e}} / N_{\mathrm{e}, \mathrm{nom}}=0.1\right.$ and 0.5$)$ and b partial power characteristics $\left(N_{\mathrm{e}} / N_{\mathrm{e}, \mathrm{nom} .}=1.0, n=600\right.$ and $\left.700 \mathrm{rpm}\right)$ 
Fig. 11 Time-frequency domain vibration acceleration run for cycles with the combustion and a misfire under conditions of the propeller screw characteristics $\left(N_{\mathrm{e}} / N_{\mathrm{e}, \text { nom. }}=0.1\right.$ and 0.5)

Fig. 12 Time-frequency domain vibration acceleration run for cycles with the combustion and a misfire under conditions of partial power characteristics $\left(N_{\mathrm{e}} / N_{\mathrm{e}, \text { nom. }}=1.0, n=600\right.$ and $700 \mathrm{rpm})$
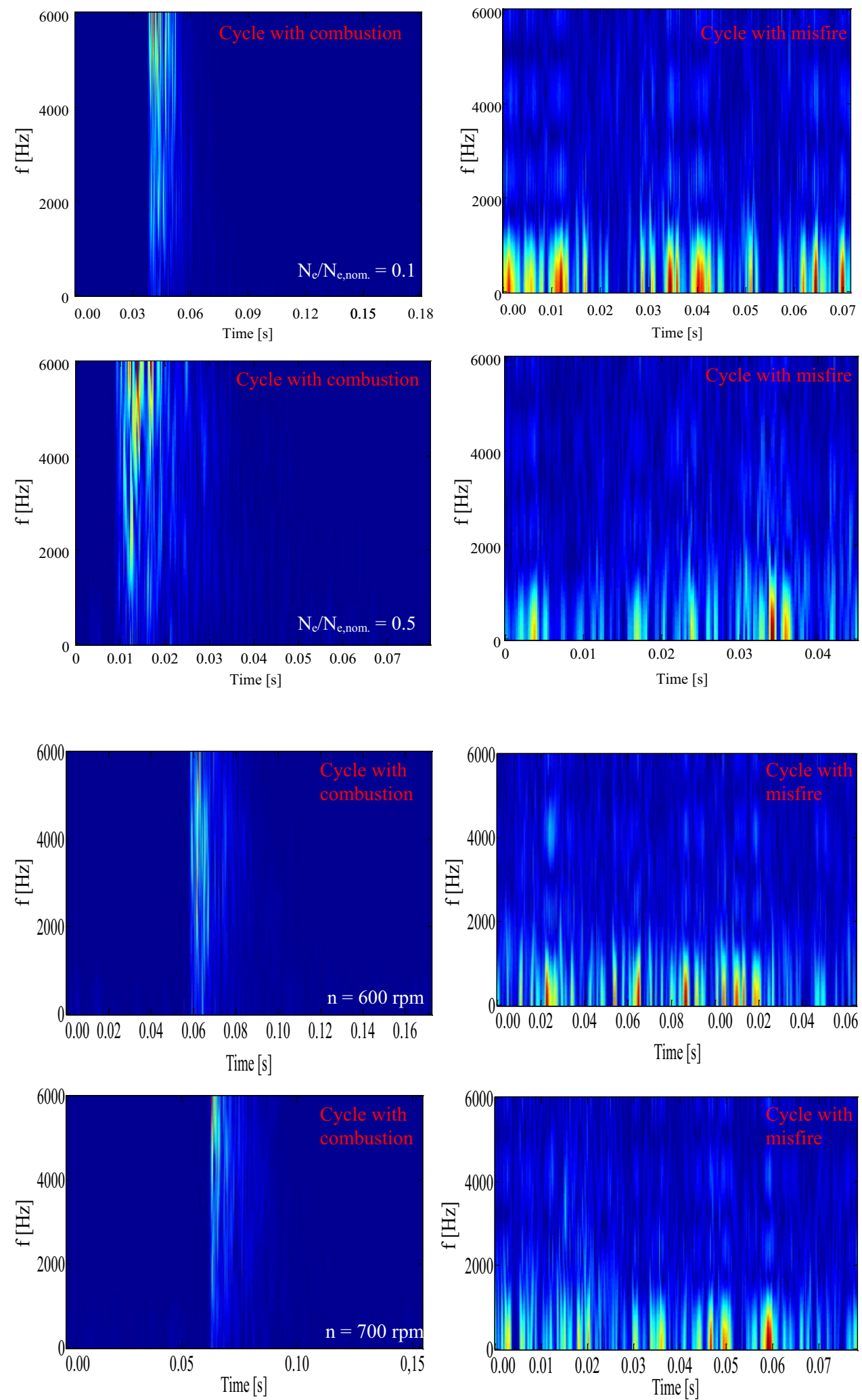

among which is particularly important is fuel supply and combustion. One of quantity methods of the process regularity evaluation, based on the diagnostic analysis, is the application of vibroacoustic process estimators for a realtime history runs of engine work cycle assessment. Evaluations of the vibration and acoustic signals need to use 
time and frequency domain analysis, and obtained maps assure exact detection, identification and quantity valuation of process parameters, also these that describe energy changes. Recognition of a combustion process in the range of frequency of $3000-5000 \mathrm{~Hz}$ was independent on engine working conditions and cylinder number. Engine operational parameters changing in one direction influenced on the specified change of time-frequency map runs.

Open Access This article is distributed under the terms of the Creative Commons Attribution 4.0 International License (http://creativeco mmons.org/licenses/by/4.0/), which permits unrestricted use, distribution, and reproduction in any medium, provided you give appropriate credit to the original author(s) and the source, provide a link to the Creative Commons license, and indicate if changes were made.

\section{References}

1. Merkisz-Guranowska A, Merkisz J, Kozak M, Jacyna M (2013) Development of sustainable road transport system. In: Brebbia CA (ed) Urban transport XIX. WIT transactions on the built environment. WIT Press, Southampton, pp 507-517

2. Merkisz-Guranowska A, Waligórski M (2016) Analysis of vibroacoustic estimators for a heavy-duty diesel engine used in sea transport in the aspect of diagnostics of its environmental impact. J Vibroeng 18(2):1346-1357

3. Korbicz J, Kościelny JM, Kowalczuk Z, Cholewa W (2002) Processes diagnostics, methods of artificial intelligence, applications. Scientific-Technical Publishing House, Warsaw

4. Merkisz J, Waligórski M (2015) Influence of operating parameters of maritime engine on its acoustic and toxic emission characteristics, combustion engines, PTNSS-2015-3360. Polish Scientific Society of Combustion Engines, Bielsko-Biała

5. Merkisz J, Waligórski M (2014) Strategy of the combustion process diagnosis in direct injection engines. Procedia Eng 96:294301 (Modelling of mechanical and mechatronic systems MMaMS 2014)

6. Jacyna M, Merkisz J (2014) Proecological approach to modelling traffic organization in national transport system. Arch Transp 30(2):31-41

7. Jacyna M, Wasiak M, Lewczuk K, Kłodawski M (2014) Simulation model of transport system of Poland as a tool for developing sustainable transport. Arch Transp 31(3):23-35 